\title{
Phytochemical and Biological Studies on Essential Oil and Leaf Extracts of Gaultheria fragrantissima Wall
}

\author{
S. Joshi (Mulmi) and P. C. Subedi \\ Central Department of Chemistry, Tribhuvan University, Kathmandu \\ e-mail:sushikajoshi@gmail.com
}

\begin{abstract}
Essential oil of Gaultheria fragrantissima Wall was isolated by hydrodistillation and GC/MS was used to find out the active constituents present in the oil. Methyl salicylate was the major compound (94.16\%) and 4-hydroxy-4methyl-2-pentanone as minor (5.84\%) of oil. Phytochemical screening of methanol, ethyl acetate, chloroform and hexane extracts of leaves showed the presence of volatile oils, alkaloids, carotenoids, steroids, triterpenes, fatty acids, phenolic compounds and glycosides. Brine Shrimp Bioassay showed the oil was cytotoxic having LC50 value of $81.3 \mathrm{mg} / \mathrm{l}$. Oils having $50 \%$ and $100 \%$ were found to be biologically active towards Staphylococcus and Kelbesia species but no positive activity was noted against Proteus and Escherichia species. Both concentrations ( $50 \%$ \& 100\%) of ethyl acetate and hexane extracts were biologically active only towards Proteus species. Further, chloroform extract was biologically inactive among the tested species. E. coli and S. aureus showed greater zone of inhibition towards methanol extracts for both concentrations.
\end{abstract}

Key words: antibacterial, cytotoxic, physiochemical parameter

\section{Introduction}

Gaultheria fragrantissima Wall belongs to family Ericaceae, is a genus of about $170-180$ species of shrubs and seven species of the Gaultheria are found in Nepal. This species (Dhasingare in Nepali language) is commonly found as wild vegetation in Nepal at altitude of 1500 to $2700 \mathrm{~m}$. It is one of the important medicinal shrubs of Nepal having maximum $1.75 \mathrm{~m}$ height. The most useful and valuable parts of the plant are leaves which are dark green in color and on steam distillation provides essential oil known as wintergreen oil. The leaves are rich in essential oil and great economic value has many medicinal and perfumery applications. It has been used to treat numerous ailments including back pain, cold symptoms, colic, headaches, fever, skin diseases, sore throats, and tooth decay (Chevallier 1996). It is used as a flavoring agent in the confectionery industry, in the manufacture of soft drinks and also used as constituent in insect repellents. The oil contains methyl salicylate as the chief constituent which is prescribed for rheumatic arthritis, sciatica and neuralgia (Apte et al. 2006).
An overdose of oil may cause degenerative changes in liver and kidneys and may cause death of the patients (Shirreff \& Pearlman 1940). The Oil is a pale yellow liquid heavier than water and strongly aromatic with a sweet characteristic odor. Methyl salicylate was found more than $95 \%$ of the water distillable oil. Beside this benzyl benzoate, menthyl acetate, $\beta$-asarone, hexanal, $\alpha$-pinene, myrcene, $\delta$-3-carene limonene, 3,7guaiadiene, $\delta$-cadinene are also found in small amount in distillable oil (Baruah 1976).

Methyl salicylate along with glucose and xylose are formed by enzymatic hydrolysis or by mild hydrolysis of the gaultherin present in leaves of $G$. fragrantssima.

\section{Methodology}

\section{Specimen collection and plant identification}

Plant specimens (leaves) were collected from the Godawari forest at altitude of about 1900m during February 2010 and identified by Professor Dr. Mohan Siwakoti, a taxonomist from Central Department of Botany, Tribhuwan University, Kathmandu. 


\section{Extraction of leaves}

The essential oil content in the crude material (45g) was extracted by hydrodistillation using the Clevenger apparatus and repeated 5 times taking fresh pieces of leaves. Upper water layer was removed by dropper and the oil thus obtained was mixed with ether. Then the upper ether with oil layer was separated using separating funnel. The separated oil was dried over anhydrous sodium sulphate (Sigma-Aldrich, USA) and $6 \mathrm{ml}$ of pure oil was obtained. Likewise, $30 \mathrm{gm}$ of powdered leaves were macerated with each $100 \mathrm{ml}$ hexane, ethyl acetate, chloroform and methanol separately for 15 days and were used for photochemical screening as well as biological studies.

\section{GC/MS analysis}

Gas chromatography-mass spectrometry (GC-MS) technique was used for analysis of the bioactive compounds present in the oil.

\section{Determination of physical parameters (Guenther 1960) \\ Specific Gravity determination}

An ignition tube, previously cleaned and dried, was weighed as $\mathrm{W}$ and was filled with the oil and was weighted as $\mathrm{w}_{1}$. The same procedure was performed using the same tube containing water and its weight was noted as $\mathrm{w}_{2}$. Specific gravity $\left(\mathrm{d}_{\mathrm{t}}\right)$ was calculated using following equation

$$
\mathrm{d}_{\mathrm{t}}=\left(\mathrm{w}_{1}-\mathrm{w}\right) /\left(\mathrm{w}_{2}-\mathrm{w}\right)
$$

Where, $\mathrm{dt}=$ Specific gravity

\section{Refractive index determination}

The refractive index of the oil was measured using Abbe's refractometer.

\section{Optical rotation determination}

Oil solution (1\%) was prepared by dissolving $1 \mathrm{gm}$ of the sample in $100 \mathrm{ml}$ methyl alcohol in volumetric flask. From this solution, $0.5 \%$ and $0.25 \%$ oil solution were prepared by proper dilution. The Polarimeter was switch on and the left for five minutes. Then the reading of Polarimeter was set to zero using distilled water in the Polarimeter tube. The Polarimeter tube was rinsed and fitted with the oil solution, fixing the bubble at the center i. e. opposite of the hole. Then the reading was noted as angle of rotation in degree by adjusting the pointer at equilibrium. Same procedure was repeated for other solutions as well. Then the specific rotation

$$
[\propto]_{\mathrm{D}}^{\mathrm{t}}=\frac{\mathrm{Q}}{1 * \mathrm{c}}
$$

Where, $\mathrm{t}=$ the temperature at the time of measurement, $\mathrm{D}=\mathrm{D}$ line of Sodium as light source, $\alpha=$ Angle of rotation of the plane of plane polarized light (mm), l=Length of Polarimeter tube and $\mathrm{c}=$ Concentration of the oil solution.

\section{Determination of chemical parameters}

Saponification value determination

Saponification value was determined by using standard procedure given by N. K.Visnoi (Visnoi 1990).

\section{Acid value determination}

Oil (0.5 gm) was accurately weighted into a $250 \mathrm{ml}$ conical flask. To this $15 \mathrm{ml}$ of neutral 95\% alcohol and $2-3$ drops of $1 \%$ phenolphthalein solutions were added. The free acid was then titrated with a standard $0.1 \mathrm{~N}$ aqueous Sodium hydroxide $(\mathrm{NaOH})$ solution adding the alkali drop wise at a uniform rate of about 30 drops per min. The content of the flask was continuously agitated. The first appearance of the red coloration that did not fade within 10 seconds was considered the end point. Then the acid value (A.V.) was calculated using the following equation,

$$
\text { A. } V .=\frac{5.61 \mathrm{x} \text { number of } \mathrm{ml} \text { of } 0.1 \mathrm{~N} \mathrm{NaOH}}{\text { Weight of sample in gram }}
$$

\section{Phytochemical screening of leaf extracts}

Concentrated leaves extracts were used for Identification of various chemical constituents, presence in leaves. The method employed for phytochemical screening was based on the procedure given by Prof. I. Ciulei (Ciulei, 1953). The different types of natural compound present in the extract are identified by their colour reaction with the different specific reagents.

\section{Brine- shrimp bioassay of essential oil}

The brine- shrimp Bioassay, was carried out to determine $\mathrm{LC}_{50}(\mathrm{mg} / \mathrm{ml})$ of oil as mentioned by J.L.Mc.Laughlin et al. (Laughlin et al.1998) .

Antibacterial screening of extracts and essential oil Inhibition of bacterial growth was tested by using the paper disc diffusion method with slight modifications.

\section{Collection of test organisms}

Employed microbial strains were obtained from the Central Department of Microbiology, T.U. and these 
strains include four different bacteria two gram-positive (Klebsiela pneumonia and Staphylococcus aureus) and two gram-negative (Escherichia coli and Proteus vulgaris).

\section{Observation of result}

After 24 hours of incubation results were recorded as the presence or absence of inhibition zones. Resulting zones of inhibition were observed and recorded as "+” and "-". The diameter of zone of inhibition (ZOI) produced by plant oil on particular bacteria was also measured with the help of millimeter ruler. The inhibitory zone around test paper discs indicates absence of bacterial growth and that was recorded as positive and absence of zone as negative. Tests were repeated three times to insure the reliability of the result.

\section{Results and Discussion}

The essential oil was founded as pale yellow fluid liquid and strongly aromatic with a sweet characteristic odor. Analysis of components presents in the oil was based on the instrumental conditions set on the GC-MS and identified by direct comparison of mass spectra with literature data (Jayasekara et al. 2002). The GC spectra of the oil given in figure 1 showed only two distinct peaks at retention times 13.51 minutes for methyl salicylate as major chemical constituents (94.16\%) and 5.75 minutes for 4-hydroxy-4-methyl-2-pentanone as minor (5.84\%). Mass spectra of methyl salicylate show molecular ion at $\mathrm{m} / \mathrm{z} 152$ with the ions corresponding to molecular formula $\mathrm{C}_{8} \mathrm{H}_{8} \mathrm{O}_{3}$ and the base peak was at $\mathrm{m} / \mathrm{z} 120$ with loss of methanol (M-32) followed by other peak at $\mathrm{m} / \mathrm{z} 92$ with loss of carbonyl group (M32-28).

The mass spectra of 4-hydroxy-4-methyl-2-pentanone show molecular ion at $\mathrm{m} / \mathrm{z} 117$ with the ions corresponding to molecular formula $\mathrm{C}_{6} \mathrm{H}_{13} \mathrm{O}_{2}$ that is protonated parent molecules. On basis of collisionally activated dissociation studies, the base peak in the electron impact mass spectrum was due to $\mathrm{CH}_{3} \mathrm{CO}+$ $(\mathrm{M} / \mathrm{Z}=43)$. This primary ion reacts rapidly along with other minor primary ions giving protonated parent molecule $(\mathrm{M} / \mathrm{Z}=117)$. The ion $(\mathrm{M} / \mathrm{Z}=101)$ is due to loss of methane from protonated parent molecules. The ion $(M / Z=99)$ was formed due to protonated mesityl oxide by loss of water from protonated parent molecule. The excited protonated mesityl oxide may either be collisionly deactivated or lose $\mathrm{CH}_{4}$ to produce an ion $(M / Z=83)$. Another peak of ion $(M / Z=59)$ is observed due to protonated diacetone for reversible reaction of protonated parent molecules. The mass spectra of both methyl salicylate and 4-hydroxy-4methyl-2-pentanone alcohol were compared with their standard previously published mass spectra and all are identical which are shown in figures 3 and 4 . The structures of these two components are given figure 4 .

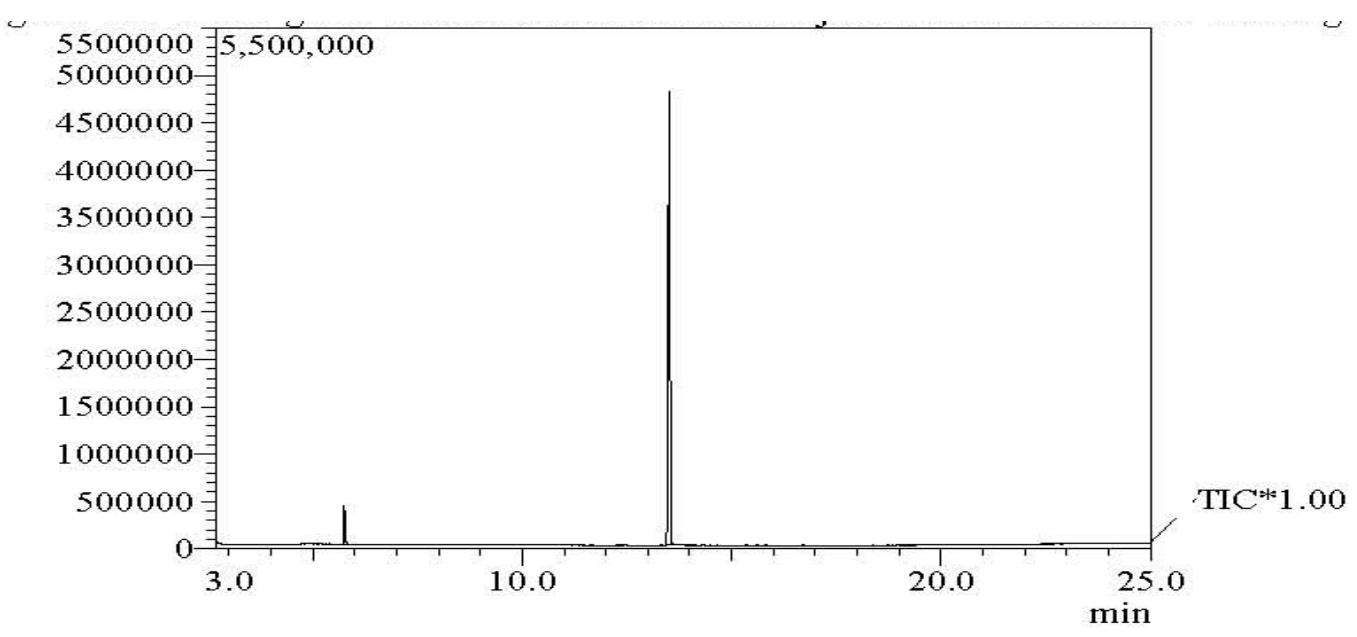

Fig. 1 . Gas chromatography for essential oil 
Nepal Journal of Science and Technology Vol. 14, No.2 (2013) 59-64

Fig. 2. Comparison of mass spectra of methyl salicylate of oil (a) with literature spectra (b

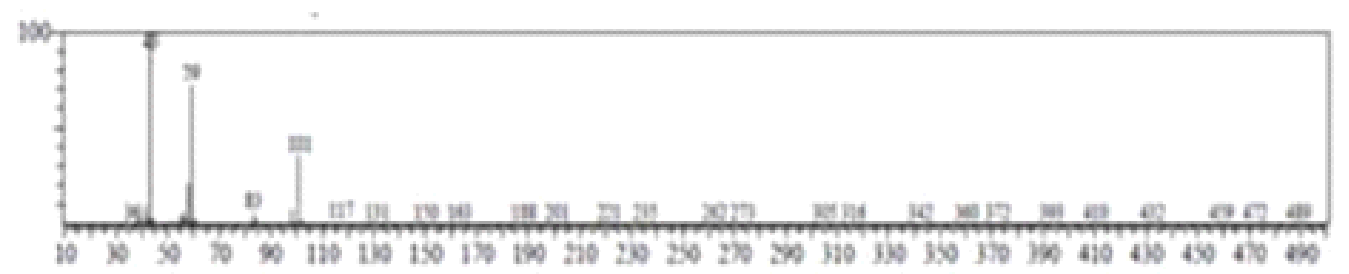

(c)

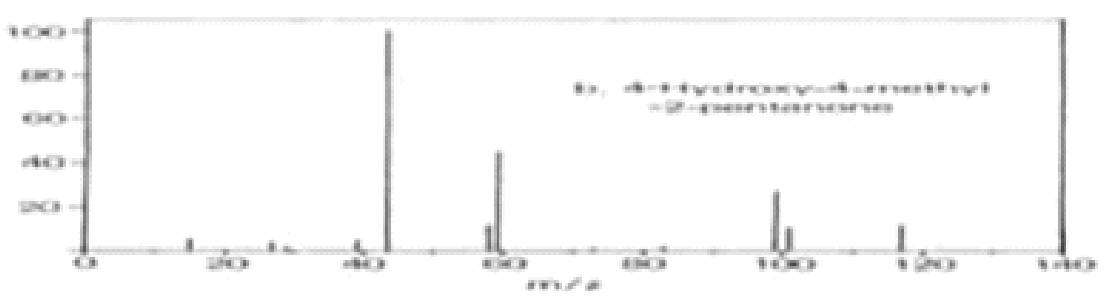

(d)

Fig. 3. Comparison of mass spectra of 4-hydroxy-4-methyl-2-pentanone of oil (c) with literature spectra (d)<smiles>COC(=O)c1ccccc1O</smiles>

(1)<smiles>CC(=O)CC(C)(C)O</smiles>

(ii)

Fig. 4. Structure of methyl salicylate (I) and 4-hydroxy-4-methyl-2-pentanone (II)

Refractive index obtained for essential oil of Gaultheria fragrantissima was 1.529 and the specific rotation value was $-10.5^{0}$. Likewise, the saponification value was found to be 353 and the specific gravity of the oil was found to be 1.17618, while the acid value was found to be 21. Essential oil was taken for the study of biological activity, which was evaluated on the basis of their toxicity towards the freshly prepared 
S. Joshi (Mulmi) \& P. C. Subedi/Phytochemical and Biological Studies.......

brine shrimps nauplii. Bioassay showed lethal concentration $\left(\mathrm{LC}_{50}\right.$ ) of the oil was found to be $81.3 \mathrm{mg} /$ l, which indicated cytotoxicity.
The phytochemical screening of various extracts were identified by the colour reaction using different the reagent and the results are presented in Table 1.

Table 1. The results of phytochemical analyses of different fractions of leaf extracts

\begin{tabular}{lllll}
\hline \multirow{2}{*}{ Constituents } & \multicolumn{5}{c}{ Leaf extracts } & \\
\cline { 2 - 5 } & Ethyl acetate & Methanol & Chloroform & Hexane \\
\hline Volatile Oils & + & + & - & - \\
Alkaloids & + & + & + & - \\
Carotinoids & + & + & - & + (triterpenes) \\
Steroids \& Triterpenes & + (steroids) & - & + & - \\
Fatty acids & + & + & - & - \\
Coumarins & - & - & - & - \\
Flavone aglycones & - & - & - & - \\
Emodins & - & - & & - \\
Quinones & - & - & + & - \\
Phenolic compounds & + & + & + & - \\
Glycosides & + & & + & +
\end{tabular}

Phytochemical screening of the leaf extract showed that volatile oils, alkaloids, carotinoids, steroids, triterpenes and fatty acids were present in the plant.
The result obtained from screening of different solvent extracts and essential oil of $G$. fragrantissima against tested bacteria are given Table no. 2 .

Table 2. Zone of inhibition of oil and leaves extracts

\begin{tabular}{|c|c|c|c|c|c|c|}
\hline \multirow[t]{2}{*}{ S.N } & \multirow[t]{2}{*}{ Oil/Extracts } & \multirow{2}{*}{$\begin{array}{l}\% \text { of extract } \\
\text { solution }\end{array}$} & \multicolumn{4}{|c|}{ Tested Micro-Organisms(Bacteria) } \\
\hline & & & $\begin{array}{l}\text { Staphylocoсcu } \\
\text { s aureus }\end{array}$ & Proteus & Klebsiella species & Escherichia coli \\
\hline 1. & Oil & $100 \%$ & $8 \mathrm{~mm}$ & - & $8 \mathrm{~mm}$ & - \\
\hline 2. & Oil & $50 \%$ & $8 \mathrm{~mm}$ & - & $8 \mathrm{~mm}$ & - \\
\hline 3. & Ethyl acetate & $100 \%$ & - & $8 \mathrm{~mm}$ & - & - \\
\hline 4. & Ethyl acetatae & $50 \%$ & -- & $8 \mathrm{~mm}$ & - & - \\
\hline 5. & Methanol & $100 \%$ & $13 \mathrm{~mm}$ & - & 8 & 12 \\
\hline 6. & Methanol & $50 \%$ & $9 \mathrm{~mm}$ & - & 8 & 11 \\
\hline 7. & Chloroform & $100 \%$ & - & - & - & - \\
\hline 8. & Chloroform & $50 \%$ & - & - & - & - \\
\hline 9. & Hexane & $100 \%$ & - & $9 \mathrm{~mm}$ & - & - \\
\hline 10. & Hexane & $50 \%$ & - & $8 \mathrm{~mm}$ & - & - \\
\hline
\end{tabular}


Oil and different solvents extracts of leaves were found to be biologically active towards tested bacteria except chloroform extract of leaves.

\section{Acknowledgements}

The authors are very much indebted to the Central Department of Chemistry, Kirtipur, Kathmandu, for providing opportunity to conduct this research in the laboratory.

\section{References}

Apte, G.S., R.A. Bahulikar, R.S. Kulkarni, M.D. Lagu, B.G. Kulkarni, H.S. Suresh, P.S.N. Rao and V.S. Gupta. 2006. Genetic diversity analysis in Gaultheria fragrantissima Wall. (Ericaceae) from the two biodiversity hotspots in India using ISSR markers. Current Science 91 (12): 1634-1640.

Baruch,A.K.S. and S. Bhagat.1976. Oil of Indian wintergreen. Indian Journal of Pharmacy 38 (2): 56-57.

Chevallier, A. 1996. The encyclopedia of medicinal plants. New York, NY. DK. Publishing Inc.
Cuilei, I, J. Red, W.W. Solomon. 1953. Methods for studying drugs. Journal of Science Food and Agriculture 4: 149-153.

Guenther, E. 1960. The essentials oils. D-van Nostrad Company, Princeton, New Jersey, New York, I, Pp. 237-306.

Jayasekara, T. K., P.C. Stevenson, S.R. Bailmain, D.L. Farman and D. R. Hall 2002.Identification of methyl salicylate as the principal volatile components in the methanol extracts of roots of Securidaca Iongepedunculata Fers. Journal of Mass Spectrum. 37: 577-580.

Press, J.R., K.K. Shrestha and D.A. Sutton. 2000. Annotated checklist of flowering plants of Nepal. The Natural History Museum, London.

McLaughlin, J.L. and L.L. Rogrers. 1998. The use of biological assays to evaluate botanicals. Drugs Information Journal 32: 513-524.

Shirreff, W. T. and L.N. Pearlman. 1940. Oil of wintergreen oil Poisoining (Report of two additional fatalcases). The Canadian Medical Association Journal 43(3): 264-268 